\title{
The applicability of Taylor's model to the drilling of CFRP using uncoated WC-Co tools: the influence of cutting speed on tool wear
}

\author{
Julián Luis Merino-Pérez* \\ Industrial Doctorate Centre in Machining Science, \\ The University of Sheffield, Sir Frederick, \\ Mappin Building, Mappin Street, Sheffield, S1 3JD, UK \\ E-mail: j.merino@sheffield.ac.uk \\ *Corresponding author

\section{Eleanor Merson} \\ Sandvik Coromant, Sandvik AB, \\ Advanced Manufacturing Park, \\ Unit 8, Morse Way, Waverley, Sheffield, S60 5BJ, UK \\ E-mail: eleanor.merson@sandvik.com
}

\section{Sabino Ayvar-Soberanis}

Advanced Manufacturing Research Centre with Boeing,

The University of Sheffield,

Advanced Manufacturing Park,

Wallis Way, Catcliffe, Rotherham, S60 5TZ, UK

E-mail: s.ayvar@amrc.co.uk

\author{
Alma Hodzic \\ Department of Mechanical Engineering, \\ The University of Sheffield, Sir Frederick, \\ Mappin Building, Mappin Street, Sheffield, S1 3JD, UK \\ E-mail: a.hodzic@sheffield.ac.uk
}

\begin{abstract}
This work investigates the applicability of Taylor's model on the drilling of CFRP using uncoated WC-Co tools, by assessing the influence of cutting speed $\left(V_{c}\right)$ on tool wear. Two different resins, possessing low and high glass transition temperatures $\left(T_{g}\right)$, and two different reinforcements, high strength and high modulus woven fabrics, were combined into three different systems. Flank wear rate gradient exhibited to be more reinforcement dependent, while the actual flank wear rate showed to be sensible also to the type of resin. In terms of tool life, all CFRP systems adjusted into a power-type tool life vs. cutting speed curve through the full range of cutting speeds (1,000 RPM to 18,000 RPM). Therefore, Taylor's model can be applied to estimate the tool life in the drilling of CFRP using uncoated WC-Co tools with good accuracy.
\end{abstract}


Keywords: Taylor model; cutting speed; tool wear; flank wear; tool life; glass transition temperature; CFRP; SEM; drilling; machining; machinability.

Reference to this paper should be made as follows: Merino-Pérez, J.L., Merson, E., Ayvar-Soberanis, S. and Hodzic, A. (2014) 'The applicability of Taylor's model to the drilling of CFRP using uncoated WC-Co tools: the influence of cutting speed on tool wear', Int. J. Machining and Machinability of Materials, Vol. 16, No. 2, pp.95-112.

Biographical notes: Julián Luis Merino-Pérez is an engineering doctorate (EngD) student at the Industrial Doctorate Centre in Machining Science, The University of Sheffield, UK. He obtained his Mechanical and Materials Engineering degrees from Universitat Politècnica de València, Spain. He is conducting his doctoral research investigating the effect of resin on tool wear in the drilling of carbon fibre reinforced plastic (CFRP) composites using tungsten carbide-cobalt (WC-Co) alloy tools.

Eleanor Merson began her career in research with a Masters in Materials Science and Engineering from Leeds University, followed by a $\mathrm{PhD}$ in characterisation of titanium alloy welds, also at Leeds University. This work focussed on crystallography, and by developing an interest in EBSD, Eleanor worked on several other projects while at Leeds. Following a short period at NAMTEC working as a technologist, she moved to Sandvik Coromant in 2010. She now works as the Composite Research Specialist for Sandvik Coromant, developing knowledge on machining of composites.

Sabino Ayvar-Soberanis is a Research Associate at the AMRC leading the research field of process modelling and residual stress measurements. $\mathrm{He}$ has worked in a range of industrial and research projects focused on the development of computer base models for machining processes as composite machining, metal cutting, and residual stress/machining distortion. He is also working and investigating different techniques for induced and bulk residual stress measurements.

Alma Hodzic is a Professor of Advanced Materials Technologies at The University of Sheffield, UK. She has been Research Director of Advanced Manufacturing Research Centre (2012-) and Director of Composite Systems Innovation Centre (2009-) at The University of Sheffield until 2014. She holds a $\mathrm{PhD}$ in Science of Engineering Materials from the Australian National University and an MEng (Dipl. Ing.) in Aeronautics from University of Belgrade. She serves as EPSRC college member, IntReader for Australian Research Council, council member of European Society for Composite Materials and Chair of British Composite Society Meetings Committee.

\section{Introduction}

The machining of fibre reinforced plastics became a field of study since the utilisation of these materials increased, due to their superior specific mechanical properties (Bhatnagar et al., 1995; Dandekar and Shin, 2012; Konig et al., 1985; Liu et al., 2012). Machining operations like trimming, turning, grinding, milling and drilling are not only intended to shape the part, however also to enable effective assembly processes for finished parts. 
The influence of cutting inputs on tool life has been well studied in metals and alloys since early in 20th century. The improvement of the productivity in machining operations is strongly associated with the reduction of tool replacement time, which ultimately lays on the ability to accurately predict the tool life. At this point, mathematical models represent an essential tool to optimise this important parameter.

In 1907, Taylor developed a mathematical model, based on empirical results, that is able to provide a good prediction of tool life (Taylor, 1907). This model establishes a correlation between the tool life and the cutting speed:

$$
V_{c} \cdot T^{n}=C
$$

where $V_{c}$ is cutting speed, $T$ is tool life and $n$ and $C$ are constants obtained empirically. An extended version of this model was also established, adding feed rate and depth of cut to the equation:

$$
V_{c} \cdot T^{n} \cdot f^{m} \cdot D^{p}=C
$$

Following Taylor's work, further models have been developed based on Taylor's model, as new alloys, metal-matrix composites (MMC's) and coatings have been developed (El-Hossainy et al., 2010; Hung et al., 1996; Korkut, 2004). However, Taylor's and Taylor-like models can only be applied within a certain range of cutting speeds(Mamalis et al., 2005).

Figure 1 depicts two tool life vs. cutting speed correlations. Curve 1 shows a monotonous inverse relationship, associated to Taylor-like models, while Curve 2 represents a more realistic dromedary-type dependence that occurs in the machining of every ferrous material (Astakhov and Osman, 1996; Mamalis et al., 2005; Taylor, 1907).

Figure 1 Typical tool life curves

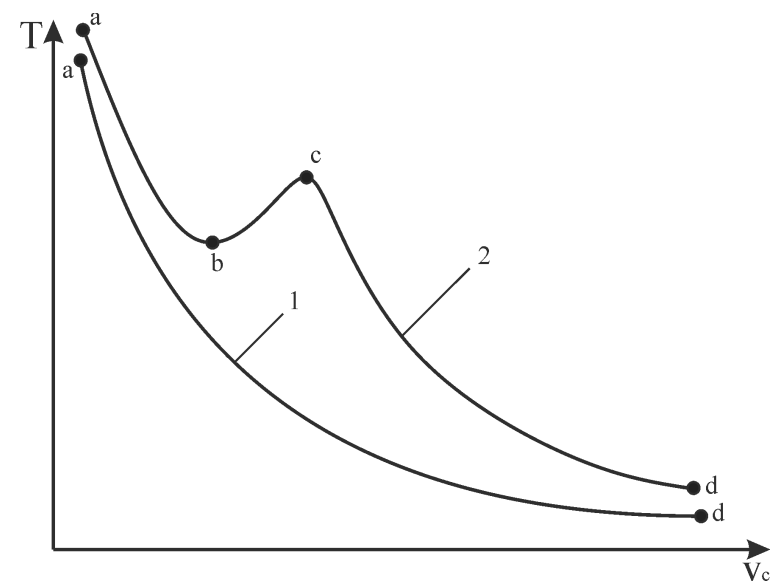

Note: Curve 1 is monotonous, associated to Taylor-like models, and Curve 2 represents a more realistic approach.

Source: Astakhov and Osman (1996), Mamalis et al. (2005) and Taylor (1907) 
In the case of fibre reinforced plastic composites, their heterogeneous structure and anisotropic properties affect the material removal operations (Bhatnagar et al., 1995; Dandekar and Shin, 2012; Konig et al., 1985). The brittle nature of polymer matrices, especially of thermosets, leads the material to be fractured (Dandekar and Shin, 2012), instead of suffering a plastic deformation process as in the machining of metals and alloys (De et al., 1994; Taylor, 1907; Xiong et al., 2013). Moreover, this breakage mode combined with a worn tool, high cutting forces and machining temperatures can produce further damage around the borehole area, which could initiate a severe damage such as delamination (Liu et al., 2012).

Research carried out by Sandvik Coromant initially showed that the drilling of carbon fibre reinforced plastic composites did not fit Taylor's model, as stated by Merson in a Sandvik Coromant internal report in 2010. In this research, six different conditions (Table 1) were tested in order to assess the influence of input parameters in tool life, represented as number of holes drilled using $6.35 \mathrm{~mm}$ uncoated WC-Co drills. The tools were tested until the selected failure criterion was reached (flank wear VB extent equivalent to $3.5 \%$ of the nominal diameter).

Table 1 Sandvik initial trials - tool life vs. cutting inputs

\begin{tabular}{lccccc}
\hline & RPM & Feed $(\mathrm{mm} / \mathrm{rev})$ & \multicolumn{3}{c}{ Tool life $\left(\mathrm{n}^{\circ}\right.$ holes) } \\
\cline { 4 - 6 } & & & Tool 1 & Tool 2 & Avg. \\
\hline Condition 1 & 2,000 & 0.08 & 150 & 150 & 150 \\
Condition 2 & 4,000 & 0.04 & 90 & 90 & 90 \\
Condition 3 & 4,000 & 0.08 & 180 & 150 & 165 \\
Condition 4 & 4,000 & 0.12 & 180 & 150 & 165 \\
Condition 5 & 6,000 & 0.08 & 150 & 150 & 150 \\
Condition 6 & 8,000 & 0.08 & 150 & 150 & 150 \\
\hline
\end{tabular}

Note: System: $10 \mathrm{~mm}$ thick Cytec 977-2 matrix + IM CF.

From the results of these trials, it can be noticed that the cutting speed did not influence the tool life, measured in number of holes, within the studied range, whereas the lowest feed rate yielded a decrease in the tool life. Other literature in the machining of CFRP presented different results (Azmi et al., 2013; Krishnaraj et al., 2012; Mamalis et al., 2005; Rawat and Attia, 2009). Mamalis claimed that Taylor's model was applicable to the drilling of CFRP, and successfully calculated $n$ and $C$ constants, obtaining an inverse $V_{c}-T$ relationship, using Taylor's model (Mamalis et al., 2005). However, the inputs used were in the range of 12,000 to 15,000 RPM (high speed machining) at a fixed feed rate of $0.1 \mathrm{~mm} / \mathrm{rev}$.

The work presented in this study covers a wider range of spindle speeds, in order to provide a better understanding about the influence of cutting speed on tool life, by studying the evolution of flank wear with the variation of the spindle speed, in drilling of CFRP composites. 


\section{Materials and methods}

\section{$2.1 \quad C F R P$}

Experiments were performed on CFRP plates manufactured at Composite Centre of the Advanced Manufacturing Research Centre with Boeing. These plates were made from woven CF + epoxy prepreg plies supplied by Cytec Engineered Materials. Initially, $700 \times 700 \mathrm{~mm}$ plates were made by vacuum bag moulding method, laying up 42 prepreg plies to approximate thickness of $10 \mathrm{~mm}$. Following the lay-up process, the plates were cured and post-cured in an autoclave, following the specifications provided by the manufacturer to achieve the maximum mechanical and thermal properties. Then, the plates were cut down to a size of $310 \times 310 \mathrm{~mm}$ using water-jet technology.

Three different CFRP systems were used in this investigation:

- $\mathrm{MTM} 44-1+\mathrm{CF} 0300$ (four plates)

- MTM44-1 + CF2216 (four plates)

- $\quad \mathrm{MTM} 28 \mathrm{~B}+\mathrm{CF} 0300$ (four plates)

MTM44-1 resin is a toughened phenol-formaldehyde (PF) based resin which features a glass transition temperature $\left(T_{g}\right)$ of approximately $220^{\circ} \mathrm{C}$. MTM28-B is a toughened epoxy DGEBA based resin which features a glass transition temperature $\left(T_{g}\right)$ of approximately $135^{\circ} \mathrm{C}$.

CF0300 is a $2 / 2$ twill carbon fabric, 3K high strength (HS) carbon fibre reinforcement, while CF2216 is a $2 / 2$ twill carbon fabric, $6 \mathrm{~K}$ high modulus (HM) carbon fibre reinforcement, both having density of $199 \mathrm{~g} / \mathrm{cm}^{2}$.

\subsection{Drilling tool}

Tests were performed using an $\varnothing 6.35 \mathrm{~mm}$ two flute double angle WC- $10 \%$ Co content uncoated Sandvik Coromant's CoroDrill 856 drill bit. The main geometry features of this tool are $120^{\circ}$ and $40^{\circ}$ point angles (chamfered geometry), $25^{\circ}$ helix angle, $12^{\circ}$ primary clearance angle, $20^{\circ}$ secondary clearance angle and $0.64 \mathrm{~mm}$ margin width. This geometry was selected as the optimum of three available geometries after a preliminary investigation, where this geometry provided an intermediate tool life. All the drill bits used in this investigation were manufactured in the same batch, having a maximum lip height variation of $25 \mu \mathrm{m}$, a maximum web eccentricity of $100 \mu \mathrm{m}$ and a chisel edge centrality of $0.05 \mathrm{~mm}$.

The tool holder used was Sandvik Coromant's CoroChuck 930 hydraulic chuck and the total measured run-out was $14 \mu \mathrm{m}$.

\subsection{Effect of $V_{c}$ on tool life}

The effect of cutting speed on tool life was assessed by measuring the tool wear (flank wear extent) as a function of spindle speed. Seven conditions, shown in Table 2, were selected to be tested in each system, by drilling 200 consecutive holes $(2,000 \mathrm{~mm})$ per condition. No coolant was used in this experiment. Each plate can potentially allocate up to 992 holes $(31 \times 32$ holes matrix $)$. 
Table 2 Test conditions for each system to assess the effect of $V_{c}$ on tool life

\begin{tabular}{lccc}
\hline & \multicolumn{3}{c}{ Inputs } \\
\cline { 2 - 4 } & $R P M$ & Feed $(\mathrm{mm} / \mathrm{rev})$ & $V_{c}(\mathrm{~m} / \mathrm{min})$ \\
\hline Condition 1 & 1,000 & 0.05 & 19.95 \\
Condition 2 & 3,000 & & 59.85 \\
Condition 3 & 6,000 & 119.70 \\
Condition 4 & 9,000 & 179.54 \\
Condition 5 & 12,000 & 239.39 \\
Condition 6 & 15,000 & 299.24 \\
Condition 7 & 18,000 & 359.08 \\
\hline
\end{tabular}

Tests were carried out using a three-axis DMG DMU 60 monoBLOCK CNC machine. Any deflection in the plates during the trials was avoided by using a backing fixture, which provided a better support.

After testing each condition, the tool was removed from the $\mathrm{CNC}$ machine, cleaned and checked for flank wear extent by using a tool maker's microscope and Clemex software.

\subsection{Cutting edge geometry}

Changes in the cutting edge geometry were measured using Alicona Infinite Focus optical system. One cutting edge per drill was inspected before and after drilling, checking the cutting edge rounding and reduction. Measurements were taken by using a fixture to tilt the tool up to the position of $45^{\circ}$, which allowed placing the tool horizontal for its correct inspection.

Figure 2 Drill sketch showing A, B and C zones

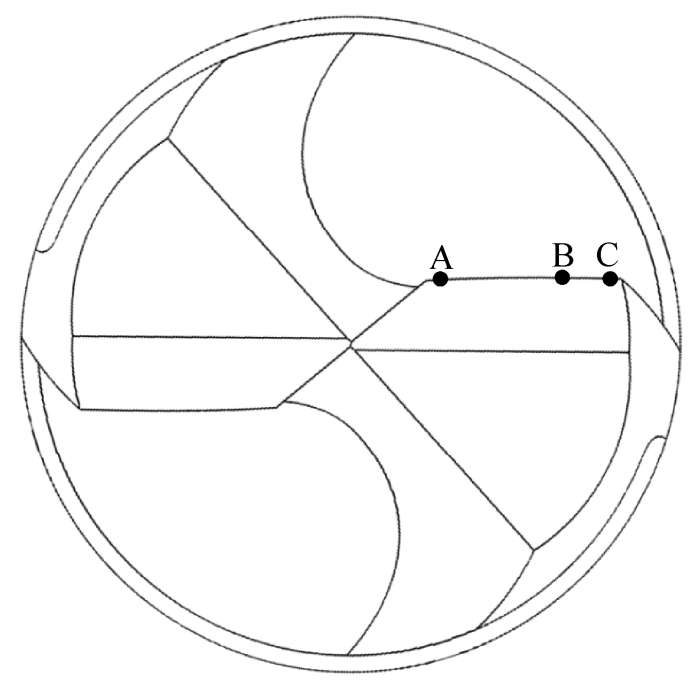

Note: $\mathrm{B}$ and $\mathrm{C}$ were the zones inspected approximately at 700 and $2,120 \mu \mathrm{m}$ distance from the beginning of the cutting edge. 
The cutting edge length was divided in three zones, named ' $A$ ', ' $B$ ' and ' $C$ ' (Figure 2), ' $B$ ' and ' $C$ ' being the zones inspected using $20 \times$ magnification lens. Zone ' $A$ ' was discarded, since the cutting speed was much lower in this zone. In order to calculate the reduction of the cutting edge in terms of distance, related to the hole quality, the profile was projected in $2 \mathrm{D}$. Then, the minimum distance between the apex and the cutting edge nose $(r)$ was measured. This operation was performed on the pre-trials and post-trials profiles, the difference between both distances was taken as the reduction of the cutting edge, $\Delta r$.

\subsection{Surface topography}

Scanning electron microscopy techniques were applied to inspect the surface topography of selected tools and work piece drilled profiles corresponding to the three CFRP systems. In order to capture the surface details at different levels, $100 \times, 500 \times$ and $1,000 \times$ magnifications were utilised. The tools and work piece drilled profiles selected to be inspected were the ones corresponding to fastest cutting speed (18,000 RPM, $359.08 \mathrm{~m} / \mathrm{min}$ ), since this exhibited the highest flank and $\Delta r$ wear rates.

The equipment used was a Carl Zeiss EVO LS25 scanning electron microscope. This device features a variable pressure mode which allows performing scans on non-conductive materials as the polymeric matrices of CFRP composites, without coating the sample.

\subsection{Drilling temperatures}

Qualitative temperature measurements at the hole exit were performed in order to provide a better understanding of the wear mechanisms developed in the drilling operation. A Micro-Epsilon thermoImager TIM 160 thermal camera was used for this purpose. The CFRP plates were clamped vertically such in a way that the thermal camera is able to record the temperature at the hole exit. In order to reach a steady temperature, a $4 \times 4$ holes matrix (16 holes in total, $10 \mathrm{~mm}$ thick) was drilled using the most aggressive cutting condition (Table 2, condition 7). In order to prevent a high cooling down rate of the tool, the settings of the $\mathrm{CNC}$ machine were adjusted to minimise the time interval between two consecutive holes. The face of the plate to be recorded was coated with a black paint of a known emissivity $(\varepsilon=0.95)$. The temperature windows were set to $50^{\circ} \mathrm{C}-250^{\circ} \mathrm{C}$ for the MTM28B-based system and $150^{\circ} \mathrm{C}-350^{\circ} \mathrm{C}$ for the MTM44-1-based systems.

\section{Results and discussion}

\subsection{Flank wear vs. spindle speed}

Figure 3 and Table 3 show the flank wear as a function of spindle speed in drilling MTM28B and MTM44-1 reinforced resins. Flank wear values are substantially lower and vary in a narrower range in MTM28B CF0300 reinforced system than in MTM44-1 CF0300, from $103 \mu \mathrm{m}$ to $130 \mu \mathrm{m}$ and from $157 \mu \mathrm{m}$ to $294 \mu \mathrm{m}$ respectively. MTM44-1 CF0300 system exhibited high flank wear at the lowest spindle speed condition (1,000 RPM) and continued to increase until reaching 3,000 RPM. 
Figure 3 Flank wear vs. cutting/spindle speed comparison after drilling 2,000 millimetres for each CFRP system

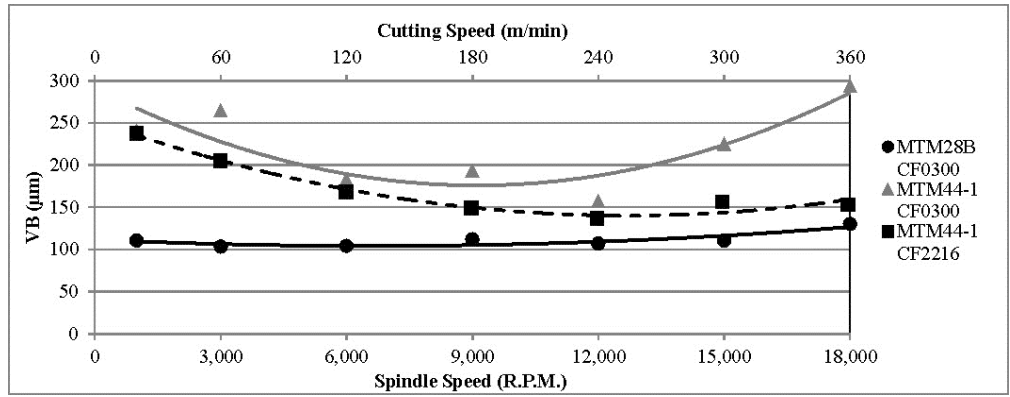

Table 3 Values of flank wear as a function of spindle speed in the drilling of CFRP composites

\begin{tabular}{lcccc}
\hline \multirow{2}{*}{$R P M$} & $\begin{array}{c}\text { Cutting speed } \\
(\mathrm{m} / \mathrm{min})\end{array}$ & $\begin{array}{c}\text { MTM28B } \\
\text { CF0300 }\end{array}$ & $\begin{array}{c}\text { MTM44-1 } \\
\text { CF0300 }\end{array}$ & $\begin{array}{c}\text { MTM44-1 } \\
\text { CF2216 }\end{array}$ \\
\cline { 3 - 5 } & 19.95 & 110.65 & 241.00 & 237.50 \\
3,000 & 59.85 & 103.20 & 264.50 & 205.10 \\
6,000 & 119.69 & 104.00 & 183.00 & 168.00 \\
9,000 & 179.54 & 112.00 & 193.50 & 149.00 \\
12,000 & 239.39 & 107.00 & 157.00 & 136.50 \\
15,000 & 299.24 & 110.50 & 225.00 & 156.00 \\
18,000 & 359.08 & 130.00 & 294.00 & 152.75 \\
\hline
\end{tabular}

From this point, flank wear decreases rapidly until 6,000 RPM. The behaviour in MTM28B is different at this early stage. Initially, at 1,000 RPM, low flank wear was measured; it continued o decrease until 3,000 RPM and remained constant until 6,000 RPM.

However, from 6,000 RPM onwards, both curves feature a similar shape which could be divided in two different intervals. Interval between 6,000 RPM to 12,000 RPM shows a concave curve with a local maximum at 9,000 RPM. The interval between 12,000 RPM and 18,000 RPM exhibits a direct linear relationship between spindle speed and flank wear, more pronounced in the case of MTM44-1 resin.

The behaviour of flank wear in both MTM44-1 systems was very different. Although both composites exhibited a decrease in flank wear between 1,000 RPM and 12,000 RPM, CF2216 system showed a constant, quasi-linear inverse correlation, and its overall flank wear values were slightly lower than CF0300. However, from 12,000 RPM on, flank wear on CF2216 system exhibited a small increase and then it remained constant until 18,000 RPM, whilst flank wear in CF0300 system increased constantly, showing a steep curve.

From these results it can be outlined that the reinforcement drives the evolution of flank wear when machining the same distance at different cutting speeds; while the resin has a strong influence in the overall flank wear values, eventually affecting the abrasiveness of the CFRP system. 


\subsection{Taylor's model in drilling CFRP}

In order to study the applicability of Taylor's model to the drilling of CFRP using uncoated WC-Co tools, it is necessary to establish a failure criterion and to extract the flank wear rate from the data obtained empirically. The wear criterion used in this study was maximum flank wear distance of $0.222 \mathrm{~mm}$ (Hocheng, 2012). Flank wear rate was calculated to extrapolate the data obtained empirically, in order to obtain the tool life (time) required to reach the failure criterion. Figure 4 shows the tool life at different spindle speeds to reach $0.222 \mathrm{~mm}$ of flank wear.

Figure 4 Time to reach the flank wear criterion $(200 \mu \mathrm{m})$ for all seven different spindle speeds, (a) MTM28B CF0300 (b) MTM44-1 CF0300 (c) MTM44-1 CF2216

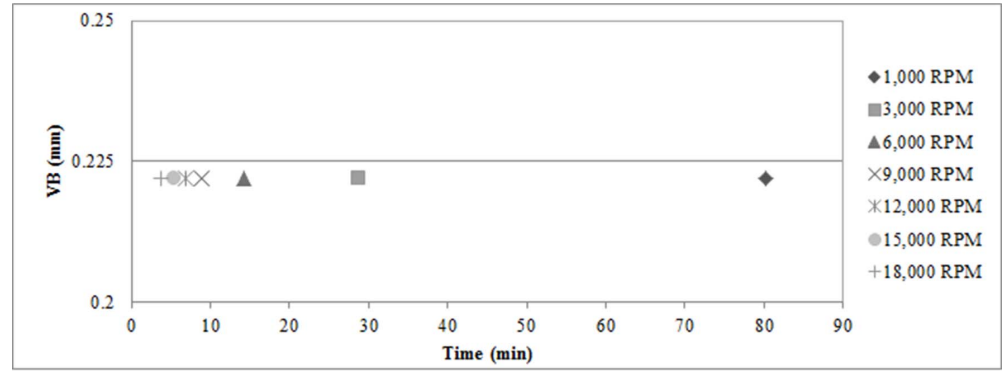

(a)

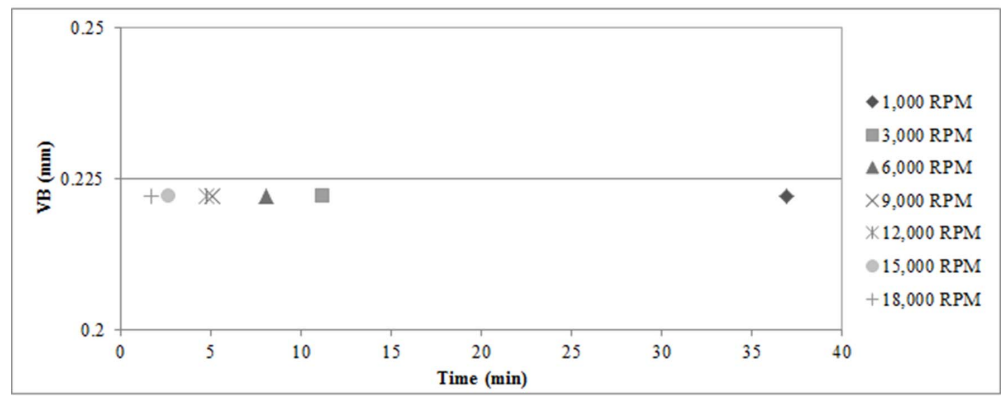

(b)

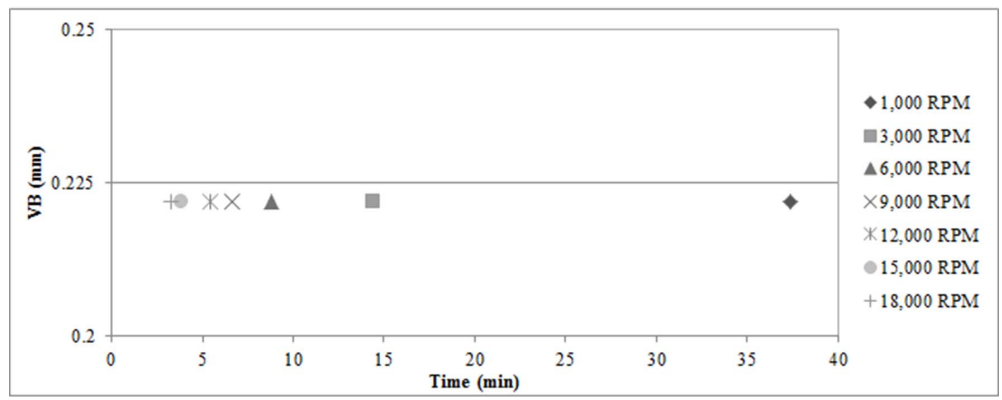

(c) 
These values can be plotted in a logarithmic tool life ( $\mathrm{min})$ vs. cutting speed $(\mathrm{m} / \mathrm{min})$ graphic, and its values can be fitted to a straight line by performing a linear regression analysis (Hocheng, 2012). Figure 5 shows the flank wear rate vs. cutting speed [Figure 5 (a)] and the log-log tool life vs. cutting speed graphics [Figure 5(b)] with their corresponding linear regression analysis. Figure 5(b) describes steeper lines for the CF0300 systems, indicating a stronger dependence of tool life on cutting speed.

Figure 5 (a) flank wear rate vs. cutting speed comparison and (b) log-log tool life plot in drilling all three different CFRP systems

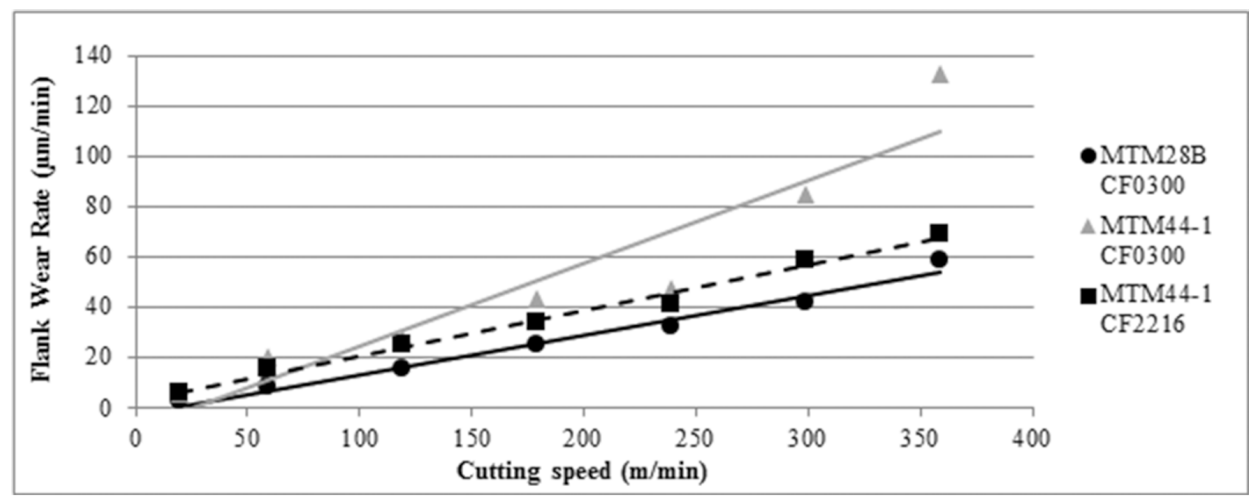

(a)

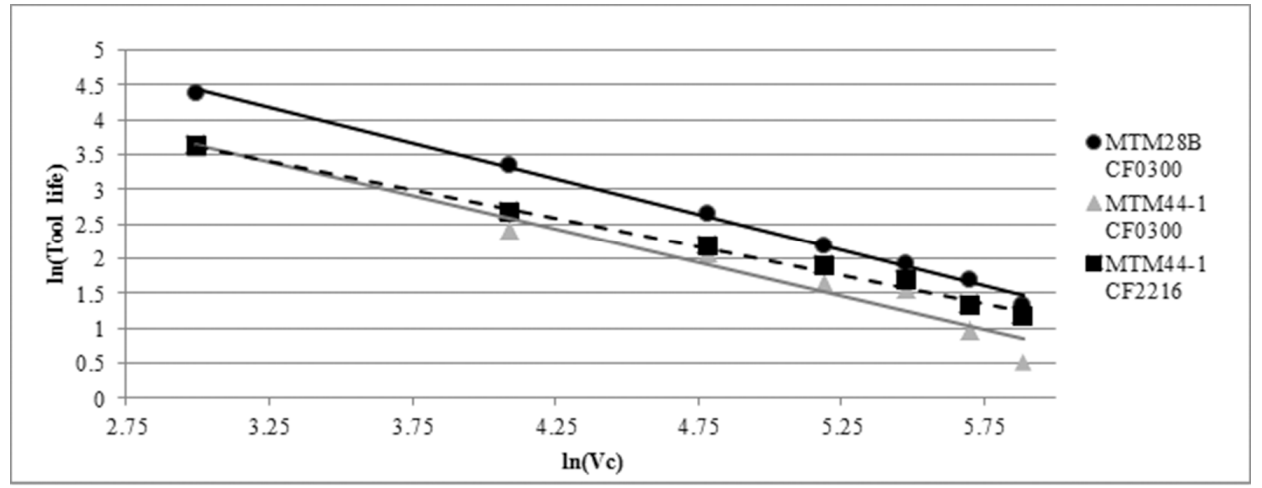

(b)

Notes: Points in both graphics have been fitted with a straight line performing a linear regression analysis.

Taylor's $n$ and $C$ coefficients can be calculated by applying standard mathematical procedures [equation (1)]. The slope $(m)$ and the y-intersect $(b)$ of the line is related to $n$ and $C$ coefficients as follows:

$$
\begin{aligned}
& m=-1 / n \\
& b=\ln C / n
\end{aligned}
$$

The calculated coefficients for the three systems are shown in Table 4. 
Table 4 Taylor's material constants corresponding to three different CFRP systems

\begin{tabular}{lcc}
\hline CFRP system & $n$ & $C(\mathrm{~m} / \mathrm{min})$ \\
\hline MTM28B CF0300 & 0.968 & 1,472 \\
MTM44-1 CF0300 & 1.037 & 867 \\
MTM44-1 CF2216 & 1.217 & 1,643 \\
\hline
\end{tabular}

Figure 6 Tool life (flank wear criterion) vs. cutting speed curves showing the predicted (line) and empirical (points) TL, (a) MTM28B CF0300 (b) MTM44-1 CF0300 (c) MTM44-1 CF2216

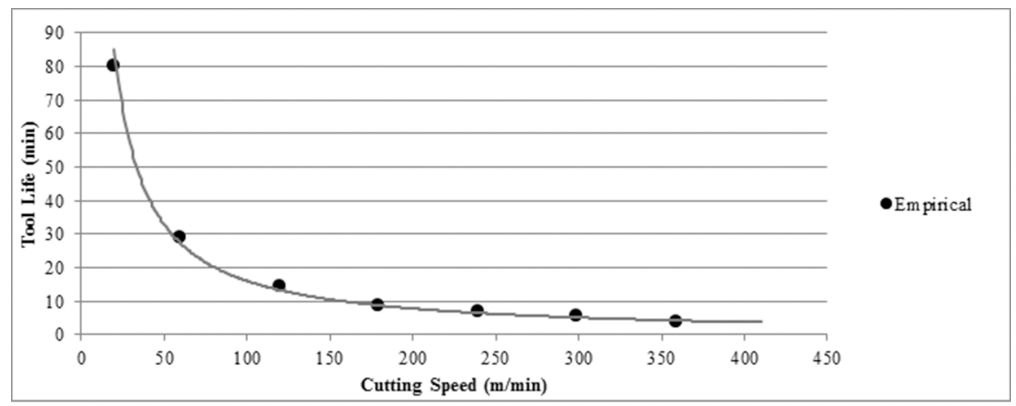

(a)

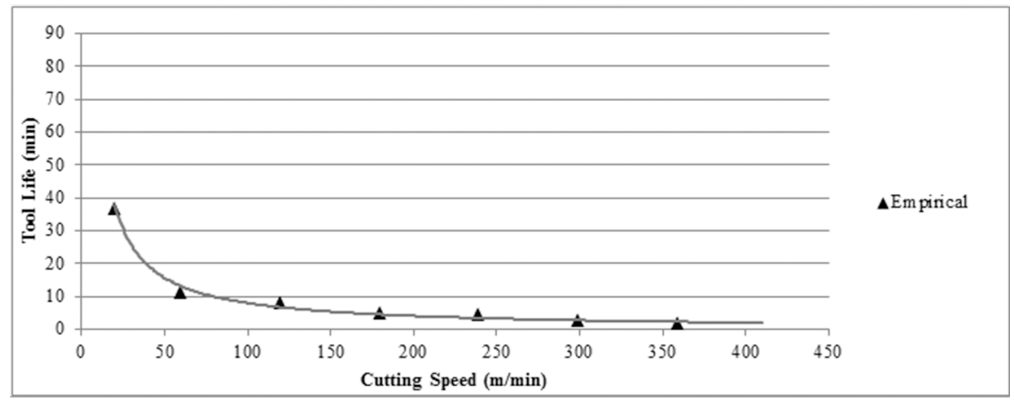

(b)

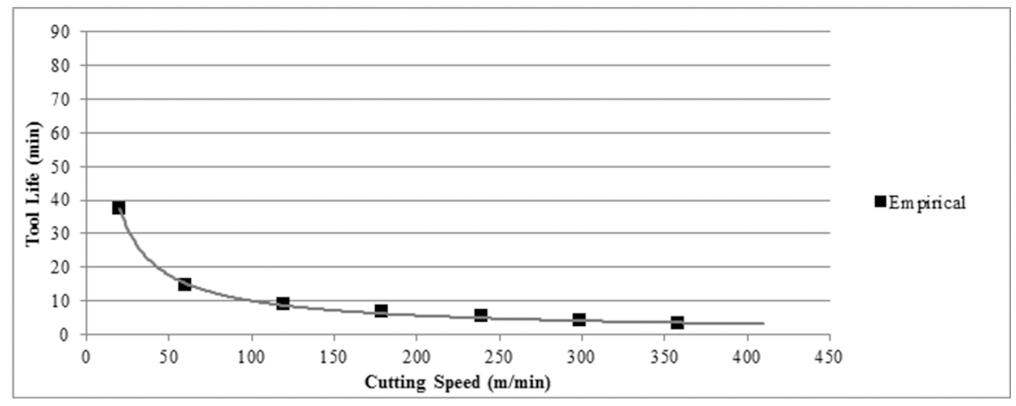

(c) 
The accuracy of the results were validated by plotting tool life values obtained using Taylor's equation and tool life values corresponding to the data obtained empirically. Figure 6 shows the tool life values for model-predicted and empirically obtained data. As it can be noticed, the model predicts with good accuracy the tool life, showing a strong dependency of tool life on cutting speed in the $0-\sim 80 \mathrm{~m} / \mathrm{min}$ range. Therefore, Taylor's equation can be applied to the drilling of CFRP in the full range of cutting speeds.

\subsection{Cutting edge geometry}

Figure 7 shows the reduction of the cutting edge, calculated as explained in 2.4 , in zone $\mathrm{C}$, where maximum wear and cutting speeds occur. Maximum $\Delta r$ occurs in MTM44-1 CF0300 and its minimum value occurs in MTM28B CF0300. The slope of the adjusted line is similar between the system sharing the same matrix, MTM44-1, which indicates a higher dependency of $\Delta r$ on the resin than on the reinforcement.

Figure 7 (a) Log-log tool life plot and (b) nose wear $(\Delta r)$ rate vs. cutting speed comparison in drilling the three different CFRP systems

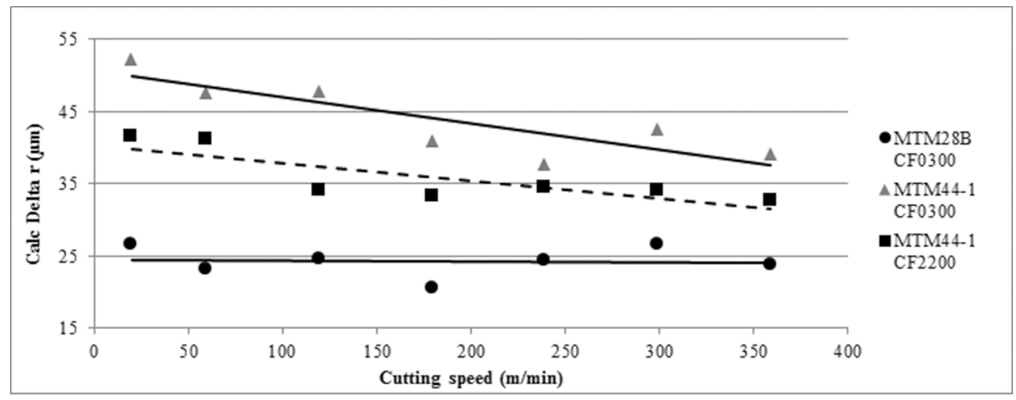

(a)

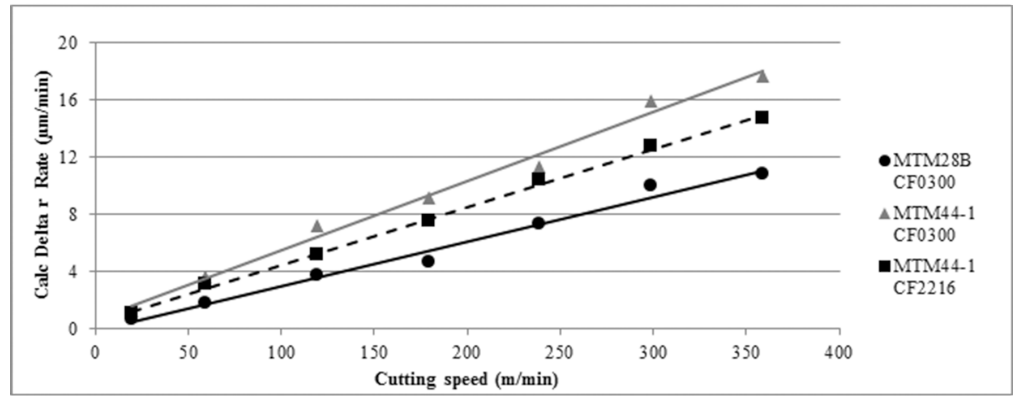

(b)

Note: Points in both graphics have been fitted on a straight line performing a linear regression analysis.

$\Delta r$ rate was calculated and it was found to vary almost constantly [Figure 7(b)]. Hence, data was analysed to fit a Taylor-like model similarly as done in 3.2. Although there is no established failure criteria for $\Delta r$, a distance of 222 microns was used to perform the analysis. Eventually, other $\Delta r$ failure criterion can be set in order to meet a certain hole quality. 
Figure 8 presents the validation of the equations obtained by plotting tool life values for calculated and empirically obtained data. The model provides a good prediction on tool life based in the selected failure criterion, and it can be outlined that cutting speed has a strong influence on the tool life in $0-50 \mathrm{~m} / \mathrm{min}$ range.

Figure 8 Tool life (nose wear $\Delta r$ criterion) vs. cutting speed curves showing the predicted (line) and empirical (points) TL, (a) MTM28B CF0300 (b) MTM44-1 CF0300 (c) MTM44-1 CF2216

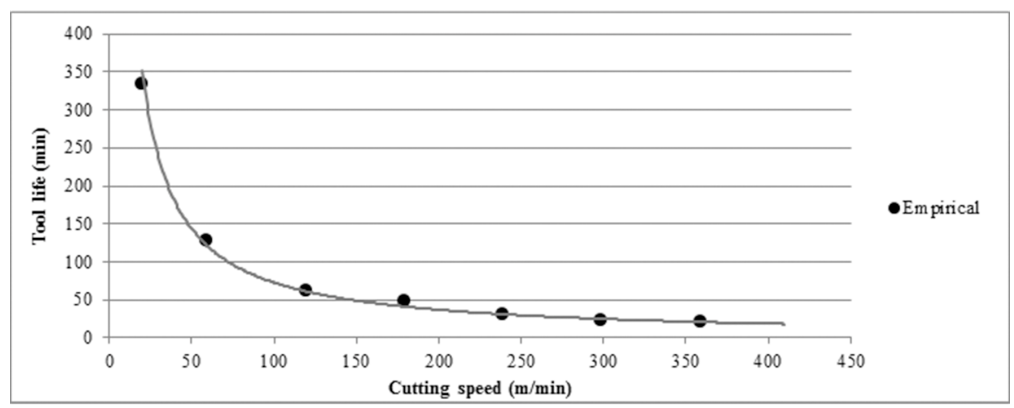

(a)

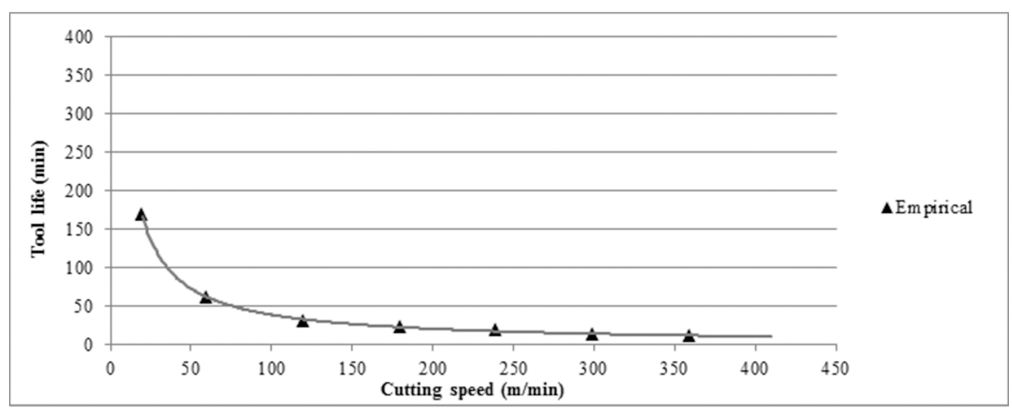

(b)

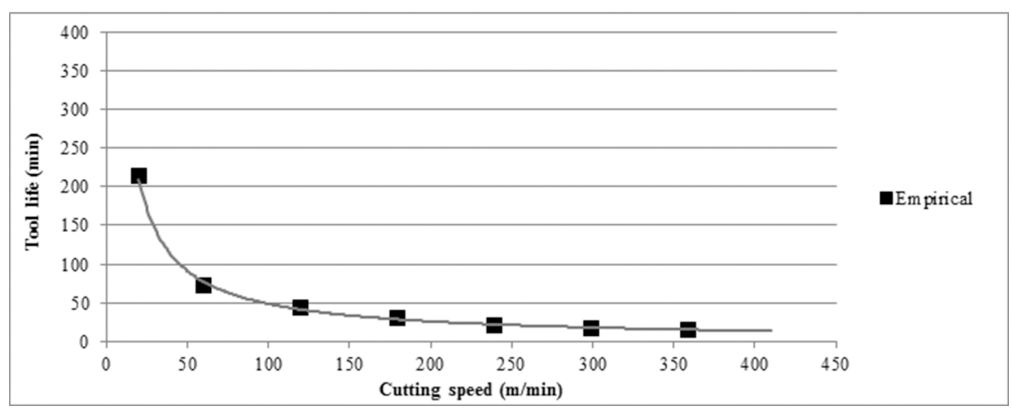

(c)

On account of the results obtained, Taylor's model does apply to the drilling of CFRP to estimate the reduction of the cutting edge $(\Delta r)$ as a function of the cutting speed. 


\subsection{Surface topography}

\subsubsection{Tools}

Figure 9 shows the flak faces of the tools used to drill MTM28B CF0300, MTM44-1 CF0300 and MTM44-1 CF2216 systems at $100 \times, 500 \times$ and $1,000 \times$ magnifications. The tool used to drill MTM28B resin-based system [Figures 9(a)-9(c)] exhibits a mild wear, appreciable by the blurred grinding marks, according to the smooth surface [Figures 9(b) and $9(\mathrm{c})]$ and the low flank wear $(125 \mu \mathrm{m})$ if compared the tools used to drill the other two systems. The cutting edge corner also features some traces of burnt resin stuck onto the surface, indicating that the temperature reached at that point exceeded the $T_{g}$ of the resin.

Figure 9 SEM micrographs - [(a), (d), (g)] 100×, [(b), (e), (h)] 500× and [(c), (f), (i) $] 1,000 \times$ magnification - showing cutting edges and flank face of the tools used to machine [(a), (b), (c)] MTM28B CF0300, [(d), (e), (f)] MTM44-1 CF0300 and [(g), (h), (i)] MTM44-1 CF2216 CFRP systems after drilling 2,000 millimetres (200 $10 \mathrm{~mm}$ thick holes) at $18,000 \mathrm{rpm}$ and $0.05 \mathrm{~mm} / \mathrm{rev}$ feed

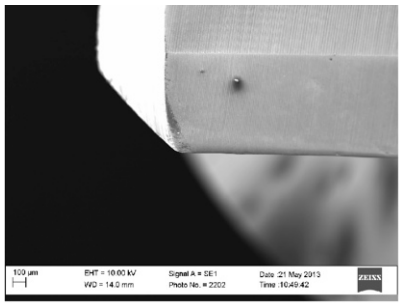

(a)

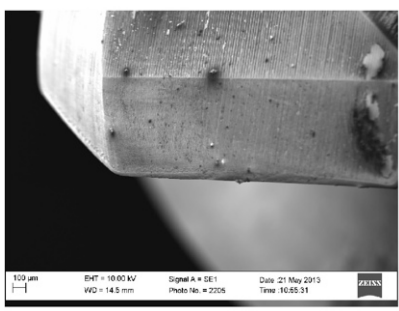

(d)

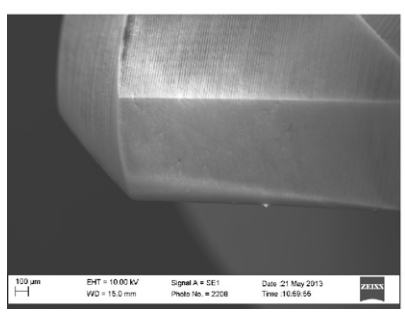

(g)

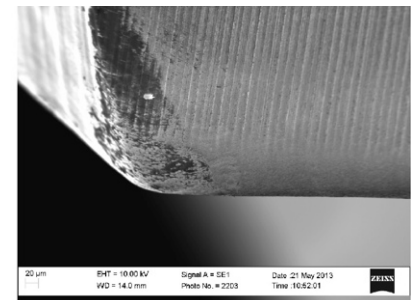

(b)

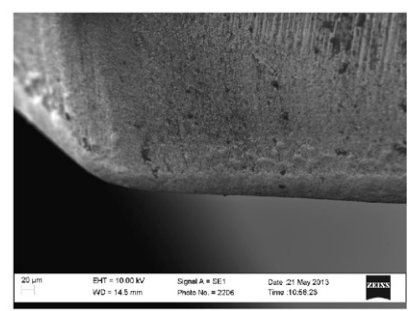

(e)

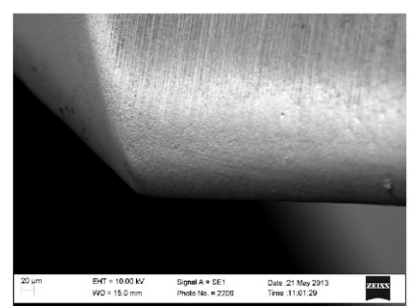

(h)

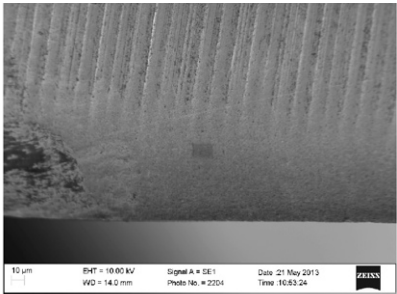

(c)

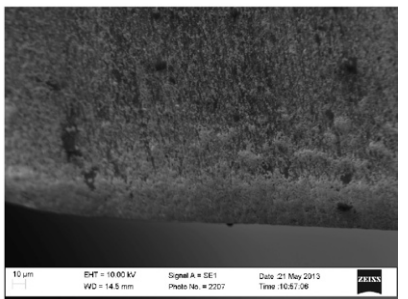

(f)

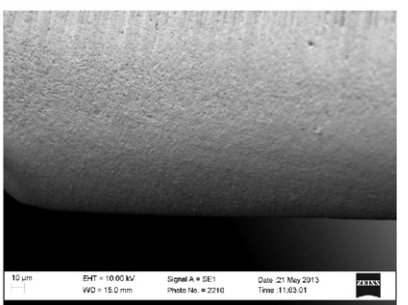

(i) 
Figures 9(d)-9(f) depict the cutting edge of the drill used to machine MTM44-1 CF0300 system, which features a number of debris and burnt resin. This is the tool which suffered the highest wear (300 $\mu \mathrm{m}$ flank wear). In Figures 9(d) and 9(e), it can be seen how the material behaved in the areas immediately close to the main cutting edge and the margin. These areas also feature a smooth surface typical of abrasive wear, which contrasts with the rough surface that can be seen on the flank face. This can be explained by a combination of high temperatures and the workpiece material springing back after being machined, causing a wear feature typical of adhesive wear [see Figure 9(f)]. The temperature in this machining operation was probably higher than the $T_{g}$ of the resin.

The tool used to machine MTM44-1 CF2216 [Figures 9(g)-9(i)] shows a mild wear and almost no presence of burnt resin [small spots can be observed on the margin, Figure 9(h)]. The area close to the cutting edge shows an average smooth surface, while the areas around the blurred grinding marks exhibit a rougher, pitted surface [Figure 9(i)]. This could help to explain how the flank wear advances: one of the possible scenario is that the composite would spring back after being machined; the high modulus carbon fibres were likely to contribute to the pitted surface, characteristic of erosive wear, followed by abrasion creating a smoother surface. According to the wear features, the temperature reached in the drill would be lower than the temperature reached in the previous tool.

\subsubsection{Work piece drilled profiles}

Figure 10 shows the drilled profiles of MTM28B CF0300, MTM44-1 CF0300 and MTM44-1 CF2216 systems at 100×, 500× and 1,000× magnifications. MTM28B CF0300 drilled profile [Figures $10(\mathrm{a})-10(\mathrm{c})$ ] shows an average roughness among the three systems machined in this study. A few cracks in $90^{\circ}$ fibres, caused by the cutting forces and torque, can also be observed. It was observed that the lag in the surface topography between $0^{\circ}$ and $90^{\circ}$ fibres was filled with debris and small machined fibres [Figures 10(b) and 10(c)].

The drilled profile corresponding to MTM44-1 CF0300 [Figures 10(e)-10(f)] exhibited the highest degree of roughness and damage on the surface among the systems examined. Despite being more brittle than MTM28B, no cracks due to the machining forces were observed. This could be explained due to the high temperatures causing softening of the matrix. Severe damage, in the form of gaps and delaminations, can be observed between $0^{\circ}, 45^{\circ}$ and $90^{\circ}$ fibres [Figure 10(f)]. A possible explanation for this phenomenon could be in the difference between the thermal coefficients and disparate stresses in the longitudinal and transversal directions.

The most even surface is observed in MTM44-1 CF2216 [Figures 10(g)-10(i)]. The temperature reached during the machining of this system would be lower compared to CF0300-reinforced system, and this would explain the appearance of several cracks in $0^{\circ}$ fibres $\left(100 \times\right.$ and $500 \times$ magnification micrographs). Under its $T_{g}$, the matrix would still retain its structural consistency, allowing these microcracks to be created. It can be noticed that these cracks do not appear in $90^{\circ}$ fibres, which may be attributed to lower resistance to the cutting forces as expected. 
Figure 10 SEM micrographs - [(a), (d), (g)] 100×, [(b), (e), (h)] 500× and [(c), (f), (i)] 1,000× magnification - showing the drilled profile of the 200th drilled hole of [(a), (b), (c)] MTM28B CF0300, [(d), (e), (f)] MTM44-1 CF0300 and [(g), (h), (i)] MTM44-1 CF2216 CFRP systems at $18,000 \mathrm{rpm}$ and $0.05 \mathrm{~mm} / \mathrm{rev}$

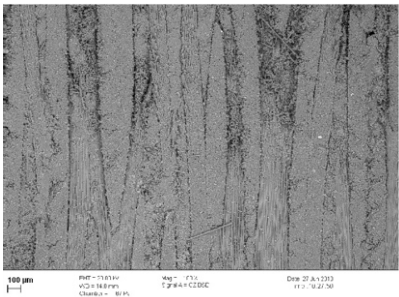

(a)

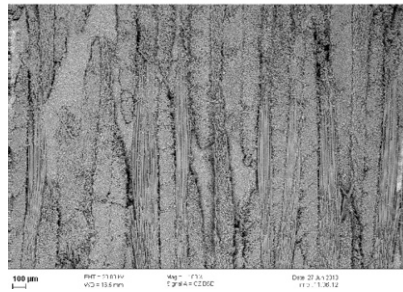

(d)

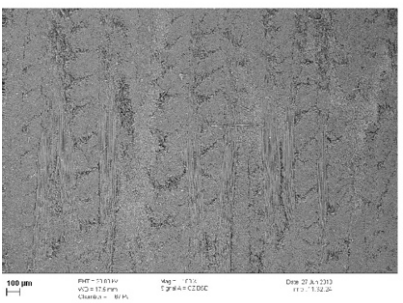

(g)

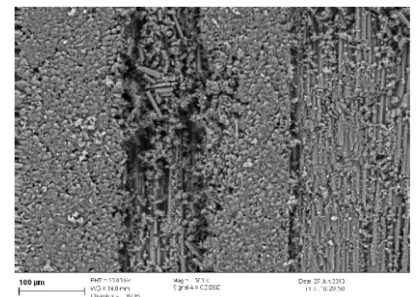

(b)

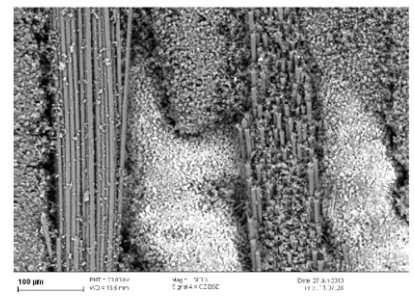

(e)

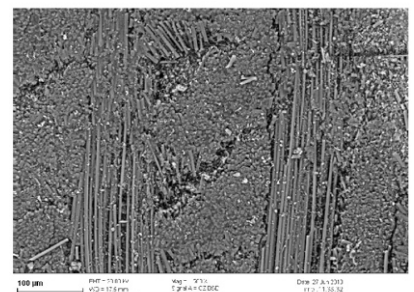

(h)

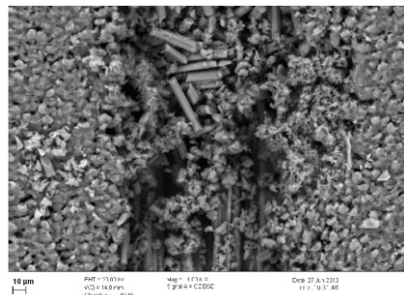

(c)

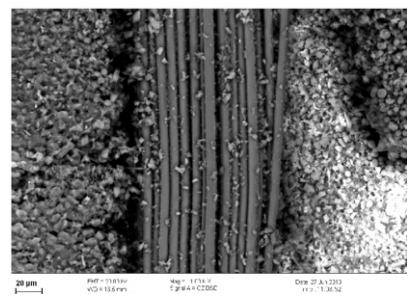

(f)

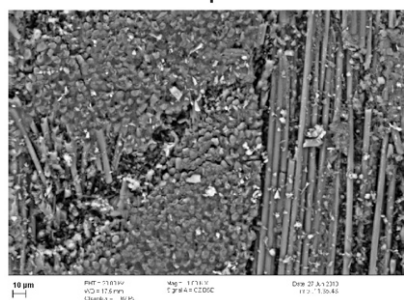

(i)

\subsection{Drilling temperatures}

Figure 11 shows the temperatures recorded at the hole exit for the last 5 holes of each drilled CFRP systems, once a steady temperature was reached. The maximum temperatures recorded were $141.1^{\circ} \mathrm{C}, 248.9^{\circ} \mathrm{C}$ and $205.8^{\circ} \mathrm{C}$ for MTM28B CF0300, MTM44-1 CF0300 and MTM44-1 CF2216 systems respectively. These temperatures are above the $T_{g}$ in CF0300-reinforced systems (high strength) whereas in the case of the CF2216-reinforced system (high modulus) the highest recorded temperature is below the $T_{g}$. The recorded temperatures support the above results and discussion, showing higher damage in the systems where the temperature exceeded $T_{g}$.

Moreover, the matrix seems to have a significant impact on the temperatures developed during the drilling operation. The low $T_{g}$ matrix softened earlier than its opposite counterpart. 
Figure 11 Temperature profiles after drilling MTM28B CF0300 (black), MTM44-1 CF0300 (grey) and MTM44-1 CF2216 (dashed black) CFRP systems recorded using a Micro-Epsilon thermoImager TIM 160 thermal camera

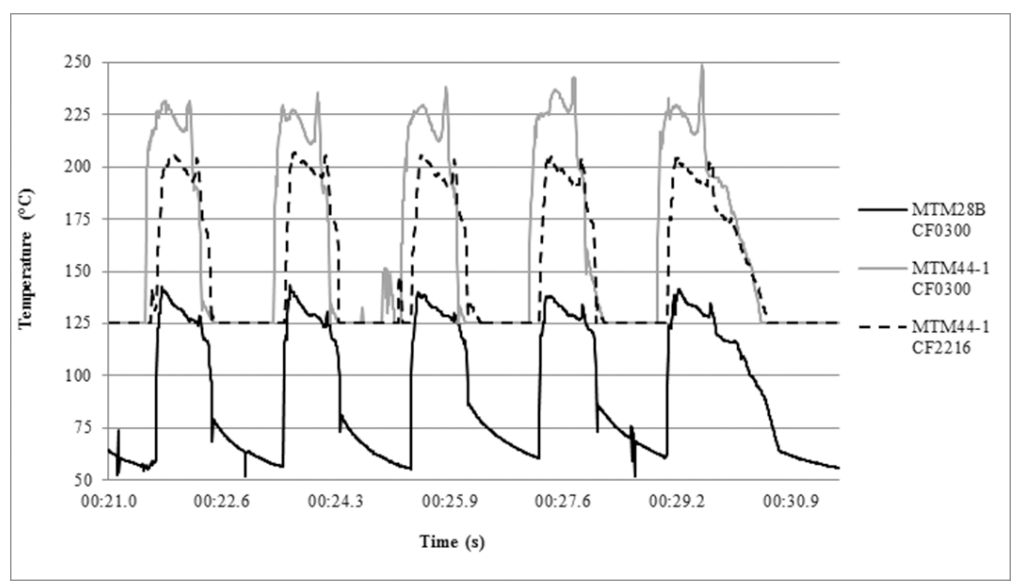

Notes: A $4 \times 4$ holes matrix was drilled in each system $(18,000 \mathrm{rpm}, 0.05 \mathrm{~mm} / \mathrm{rev}$ feed $)$ to assure a steady temperature. The temperature profiles corresponding to the last five holes are represented.

\section{Conclusions}

Based on the experimental results obtained in drilling of three different CFRP systems (two different resins combined with two different reinforcement types) using uncoated WC-Co tools, on a wide range of cutting speeds $(20-360 \mathrm{~m} / \mathrm{min})$ at a fixed feed rate of $0.05 \mathrm{~mm} / \mathrm{rev}$; the following conclusions can be extracted:

- Flank wear rates for the three systems studied showed a linear dependence on cutting speed. High $T_{g}$ resin-based systems exhibited higher flank wear rates than the low $T_{g}$ resin-based system, and high strength reinforcement exhibited higher flank wear rates than high modulus reinforcement.

- A possible reason for this behaviour could be related to the temperature developed during the process. High $T_{g}$ resins are able to maintain their mechanical properties at higher temperatures, hence the reinforcement would be held in its position, increasing the abrasiveness of the system.

- On the other hand, the higher abrasiveness exhibited by high strength reinforcement could be explained by a brushing effect as the consequence of its strength, while high modulus reinforcement suffered a brittle fracture.

- Tool life as a function of cutting speed fit Taylor's model with a high degree of confidence in the three systems, both in flank wear and $\Delta r$ criteria. Hence, Taylor's model can be applied to the drilling of CFRP.

- Temperatures developed during the process at the tool-workpiece interface, cutting mechanisms of both reinforcements and feed rate require more investigation in order to clarify and quantify their effect on the drilling of CFRP. 


\section{Acknowledgements}

This work was co-funded through the EPSRC Industrial Doctorate Centre in Machining Science (EP/I01800X/1) and by Sandvik Coromant.

\section{References}

Astakhov, V.P. and Osman, M.O.M. (1996) 'Correlations amongst process parameters in metal cutting and their use for establishing the optimum cutting speed', Journal of Materials Processing Technology, Vol. 62, Nos. 1-3, pp.175-179.

Azmi, A.I., Lin, R.J.T. and Bhattacharyya, D. (2013) 'Tool wear prediction models during end milling of glass fibre-reinforced polymer composites', International Journal of Advanced Manufacturing Technology, Vol. 67, No. 4, pp.701-718.

Bhatnagar, N., Ramakrishnan, N., Naik, N.K. and Komanduri, R. (1995) 'On the machining of fiber reinforced plastic (FRP) composite laminates', International Journal of Machine Tools and Manufacture, Vol. 35, No. 5,pp.701-716.

Dandekar, C.R. and Shin, Y.C. (2012) 'Modeling of machining of composite materials: a review', International Journal of Machine Tools and Manufacture, June. Vol. 57, pp.102-121.

De, E., Julien, H. and Laurent, C.S. (1994) 'Prediction of tool life in turning aluminium matrix composites', Materials and Design, Vol. 15, No. 5, pp.287-293.

El-Hossainy, T.M., El-Zoghby, A.A., Badr, M.A., Maalawi, K.Y. and Nasr, M.F. (2010) 'Cutting parameter optimization when machining different materials', Materials and Manufacturing Processes, October, Vol. 25, No. 10, pp.1101-1114.

Hocheng, H. (2012) Machining Technology for Composite Materials: Principles and Practice, Woodhead Publishing, Cambridge.

Hung, N.P., Khor, K.A., Phua, Y.S. and Lee, H.F. (1996) 'Machinability of aluminum alloys reinforced with silicon carbide particulates', Journal of Materials Processing Technology, Vol. 56, Nos. 1-4, pp.966-977.

Konig, W., Wulf, C., Gral, P. and Willerscheid, H. (1985) 'Machining of fibre reinforced plastics', Annals of the CIRP, Vol. 34, No. 2, pp.537-548.

Korkut, I. (2004) 'Materials \& design determination of optimum cutting parameters during machining of AISI 304 austenitic stainless steel', Materials and Design, Vol. 25 No. 4, pp.303-305.

Krishnaraj, V., Prabukarthi, A., Ramanathan, A., Elanghovan, N., Senthil Kumar, M., Zitoune, R. and Davim, J.P. (2012) 'Optimization of machining parameters at high speed drilling of carbon fiber reinforced plastic (CFRP) laminates', Composites Part B: Engineering, Vol. 43, No. 4, pp.1791-1799.

Liu, D., Tang, Y. and Cong, W.L. (2012) 'A review of mechanical drilling for composite laminates', Composite Structures, Vol. 94, No. 4, pp.1265-1279.

Mamalis, A.G., Kundra, J. and Horva, M. (2005) 'On a novel tool life relation for precision cutting tools', Journal of Manufacturing Science and Engineering, Vol. 127, No. 2, pp.328-332.

Rawat, S. and Attia, H. (2009) 'Wear mechanisms and tool life management of WC-Co drills during dry high speed drilling of woven carbon fibre composites', Wear, Vol. 267, Nos. 5-8, pp.1022-1030.

Taylor, F.W. (1907) On the Art of Cutting Metals, American Society of Mechanical Engineers, New York.

Xiong, J., Guo, Z., Yang, M., Wan, W. and Dong, G. (2013) 'Tool life and wear of WC-TiC-Co ultrafine cemented carbide during dry cutting of AISI H13 steel', Ceramics International, Vol. 39, No. 1, pp.337-346. 